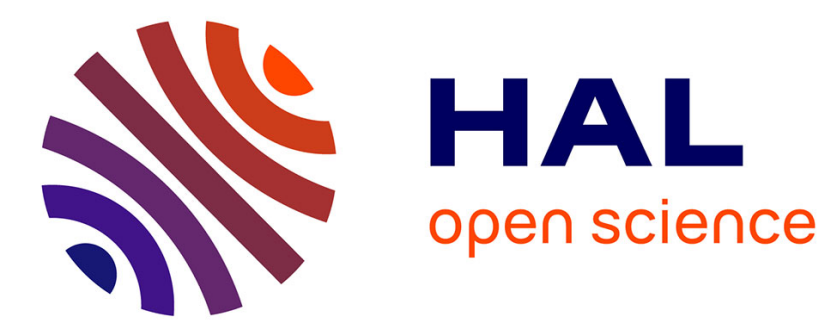

\title{
Marking small hive beetles with thoracic notching: effects on longevity, flight ability and fecundity
}

Lilia Guzman, Amanda Frake, Thomas Rinderer

\section{To cite this version:}

Lilia Guzman, Amanda Frake, Thomas Rinderer. Marking small hive beetles with thoracic notching: effects on longevity, flight ability and fecundity. Apidologie, 2012, 43 (4), pp.425-431. 10.1007/s13592011-0107-8 . hal-01003530

\section{HAL Id: hal-01003530 \\ https://hal.science/hal-01003530}

Submitted on 1 Jan 2012

HAL is a multi-disciplinary open access archive for the deposit and dissemination of scientific research documents, whether they are published or not. The documents may come from teaching and research institutions in France or abroad, or from public or private research centers.
L'archive ouverte pluridisciplinaire HAL, est destinée au dépôt et à la diffusion de documents scientifiques de niveau recherche, publiés ou non, émanant des établissements d'enseignement et de recherche français ou étrangers, des laboratoires publics ou privés. 


\title{
Marking small hive beetles with thoracic notching: effects on longevity, flight ability and fecundity
}

\author{
Lilia I. de Guzman, Amanda M. Frake, Thomas E. Rinderer \\ USDA-ARS, Honey Bee Breeding, Genetics and Physiology Laboratory, 1157 Ben Hur Road, Baton Rouge, LA \\ 70820-5502, USA
}

Received 1 June 2011 - Revised 9 September 2011 - Accepted 18 October 2011

\begin{abstract}
We tested two marking techniques for adult small hive beetles (SHB): dusting and thoracic notching. The use of blue and red chalk dusts to mark beetles was not persistent and caused early death of SHB with an average survival of $52.6 \pm 23.8$ and $13.9 \pm 7.3$ days, respectively. In contrast, notched beetles survived longer (mean $=353.6 \pm 5.3$ days) with the last beetle dying after 383 days. Likewise, notched beetles (presumed to be injured because of oozing hemolymph from the notched area) also lived long with an average of 193.6 \pm 38.8 days. Notching also resulted in a high rate of recovery; $81 \%$ for beetles introduced directly into a nucleus colony, and 59\% and $66 \%$ for a nucleus colony and pole traps, respectively, for beetles released inside a screen tent. These high recovery rates confirmed that notching did not interfere with the beetles' ability to fly. However, it appeared that notched females laid more eggs than those that were not notched both with multiple ( $171.70 \pm 11.20$ vs $126.87 \pm 10.27$ eggs per day) and single (70.02 \pm 5.45 vs $57.97 \pm 5.12$ eggs per day) pairs for a period of 1-3 days. Whether or not notching affects lifetime fecundity of females was not assessed in this study. Nevertheless, notching is a permanent mark for SHB and thus, may be useful in many ecological studies or in studying the efficacy of lures and traps for SHB control.
\end{abstract}

Aethina tumida / mark / notch / recapture / survival / fecundity / flight activities

\section{INTRODUCTION}

Small hive beetle (SHB) is a honey bee pest of increasing concern to beekeepers in the warmer regions of the USA. Its recent establishment in the tropical islands of Hawaii had caused extensive colony mortality; about 55\% on the Big Island of Hawaii alone (Connor 2011). Hence, the development of effective control measures is urgently needed.

The ability to mark insects allows researchers to conduct various ecological studies including population density, dispersal, host-selection behavior, and feeding habits (Hagler and Jackson 2001). Although these types of studies provide

Corresponding author: L.I. de Guzman,

lilia.deguzman@ars.usda.gov

Manuscript editor: Peter Rosenkranz information needed in the formulation of control strategies (Winder 2004), they have been limited with SHB.

SHB research is now focused on finding effective control measures such as the use of lures and traps. Several designs of in-hive SHB traps are now commercially available. However, the effectiveness of most of these traps is inadequate. Generally, the efficiency of a SHB trap is measured by the decrease of the SHB population in a colony which is estimated by counting the initial SHB population in the colony before the trap is installed, the number of SHB that are lured into the trap, and the final population of SHB in the colony at the end of the experiment. Because of the ability of SHB to fly in and out of the colonies, either some of the initial inhabitants leave the hives or new cohorts of beetles from nearby colonies or 
apiaries invade the hives constantly. This unrestricted movement of beetles makes it difficult to establish accurate efficiency of SHB traps. Hence, marking SHBs may be useful in conducting these types of studies.

Hagler and Jackson (2001) reviewed techniques of mark-release-recapture for marking insects, which include the use of dusts, paints, dyes, immunoglobulin markers, notching elytra (chitinous wings of beetles), abraded and branded marks, radio-isotopes, and rare earth elements. For marking beetles, abrasion and branding have been employed specifically in carabid beetles (Winder 2004). Although proven to be reliable, these two techniques are costly and labor intensive. Finding a technique to mark SHB adults is very challenging because of their small size, waxy elytra, and lack of hairs. Testors ${ }^{\circledR}$ model car paint has been used in marking SHB adults by painting the posterior end of the ventral side of the abdomen (Nolan and Hood 2008). However, only a small proportion (about 13\%) of the beetles was recovered because the paint did not persist on the shiny or waxy body surface of adult SHBs. A similar problem has been experienced in painting adult scarab beetles (Goldwasser et al. 1993).

Dusts or powders are the most useful materials used for marking large insects or insects with hairy surfaces (Hagler and Jackson 2001). However, some beetles such as the boll weevils (Taft and Agee 1962) and Japanese beetles (Polivka 1949) have been marked successfully using a powdered form of fluorescent pigments. On the other hand, ear notching is commonly used to mark animals such as swine and cattle. In insects, it has been found effective in marking the pronotum of grasshoppers, crickets, katytids, and even cockroaches without inflicting any harm on them (Gangwere et al. 1964). The use of triangular and square notches was first used by marking the elytra of scarabid beetles (Goldwasser et al. 1993). The authors successfully marked thousands of scarabid beetles of the genus Cyclocephala, which range in size from 10 to $25 \mathrm{~mm}$. This technique did not affect flight activities or longevity of the scarab beetles. We therefore investigated the effectiveness of notching as a permanent mark for SHB adults in comparison to the dusting technique.

\section{MATERIALS AND METHODS}

\subsection{Effect of dusting and notching on the longevity of marked SHB}

Initially, the elytra of SHB were notched for this study but this resulted in breakage, which was presumed to restrain flight activities of the beetles. Thus, we marked SHB adults by making a triangular notch along the posterior margin of the thorax and compared its effectiveness to dusting technique using blue and red standard marking chalk (Irwin ${ }^{\circledR}$ Industrial Tools, Huntsville, NC).

Newly emerged SHBs reared in the laboratory were used in this experiment. Upon emergence, the SHB adults were collected and placed in $30 \times 30 \times 30 \mathrm{~cm}$ holding containers with cotton balls (placed in a netting) soaked in honey solution (1 honey/1 water) as food. About 200 unsexed beetles were marked with chalk dust: 100 beetles each for the red and blue dusts. To obtain dusted adult SHBs, $0.1 \mathrm{~g}$ of powder was used to coat the inside surface of a quart Ziploc ${ }^{\circledR}$ plastic bag by shaking the bag to distribute the dust evenly throughout the bag. Thereafter, 100 adult SHBs were introduced into the bag and the bag was gently shaken for about $10 \mathrm{~s}$ to coat them. For the notched group, another 100 unsexed SHBs were used. The pronotum of SHB has a sinuated posterior margin. The tip of either right or left margin was notched (see Figure 1) using the tip of an iris scissor $(8 \mathrm{~mm})$ by simply holding the insect between two fingers. Notching was conducted under a dissecting microscope.

All test beetles were placed in plastic containers (volume $=75 \mathrm{~mL}$ ) with ten beetles per container (notched $=10$, blue dust $=10$, red dust $=10$ ). One container represented one replication. Also, beetles that had oozing hemolymph from the notched area (referred to as injured) were placed in different containers. Only five containers with ten injured beetles each were established. Each container was provided with one cotton ball (placed in a netting to prevent SHB's legs from being entangled) soaked in 1:1 honey/water solution which was replaced every week. The moistened cotton balls served as a food source and also provided 


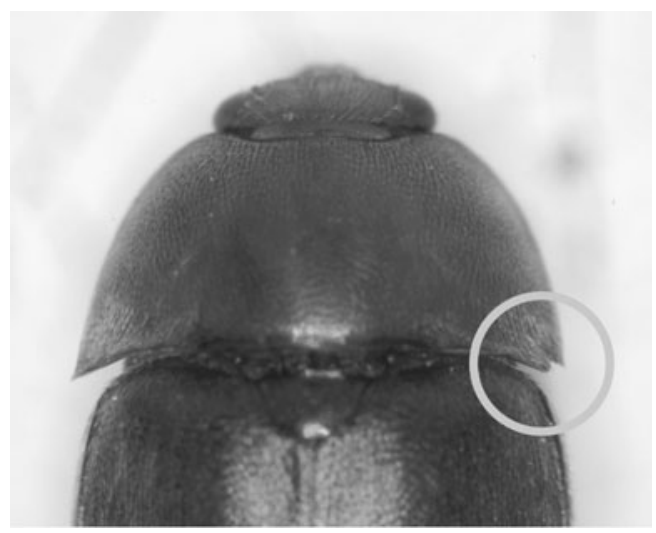

Figure 1. A small hive beetle with a triangular notch on the posterior margin of the thorax.

moisture for the beetles. Mortality was examined every day until the last beetle died. Although test beetles were not anesthetized, they were handled with extreme care to minimize further injuries or stress.

\subsection{Recapture rate and effect of notching on SHB flight activities}

This study was conducted inside a $4.57 \times 3.96 \times$ 2.13 m (length $\times$ width $\times$ height) screen tent (Ozark Trail Screen House). A preliminary trial showed that all dusted beetles $(n=100)$ released inside a six-frame colony lost their mark after $15 \mathrm{~h}$. Hence, the following experiments were focused on notched beetles. Three experiments were conducted. Experiment 1 determined the $24 \mathrm{~h}$ recovery rate of notched beetles after introducing them into a six-frame nucleus colony. Two trials were conducted using a total of 183 notched beetles. For experiment 2, notched beetles were released about $30 \mathrm{~cm}$ behind a six-frame nucleus colony located at the middle of the tent. Hence, the notched beetles were forced to fly in order to invade the colony via the hive entrance. Three trials were conducted $(n=300 ; 100$ per trial). In the third experiment, the six-frame nucleus colony was replaced with a pole with six polyvinyl chloride pole traps baited with fermented pollen dough (Arbogast et al. 2007; de Guzman et al. 2011). The pole traps were hanging at $46 \mathrm{~cm}, 1 \mathrm{~m}$, and $2 \mathrm{~m}$ high; two traps per height. Notched beetles were released at the middle of the tent. Two trials were conducted using 200 notched beetles per trial.

\subsection{Effect of notching on SHB fecundity}

Fecundity of marked beetles was evaluated using multiple and single pairs of females and males. For the multiple mating, rearing containers $(10.5 \times 8.5 \times 7.5 \mathrm{~cm})$ were prepared as described by de Guzman and Frake (2007): three containers for the notched group and three containers for the control group (no notch). In brief, each container contained 20 newly emerged adult SHBs (ten females and ten males), ten bee pupae as food, $\sim 5 \mathrm{~g}$ Mega bee patty (Dadant and Sons, Inc., Hamilton, IL) and two moistened (with honey solution) cotton balls (placed in a netting) for food and moisture. Two egg laying slides were also provided. After $24 \mathrm{~h}$, all beetles were removed, and the eggs were placed back into the incubator for hatching to facilitate counting. Egg laying was only monitored for 1 day.

For the single-pair mating, adult beetles were randomly selected from 2- to 7-day-old laboratoryreared beetles fed with honey solution (in cotton balls placed in a netting) inside a holding container. The notched group consisted of 50 females (notched on the right margin of the thorax) and 50 males (notched on the left margin of the thorax). Beetles (50 females and 50 males) used in the control group were not notched. Each pair (one male and one female) was placed in a scintillation vial $(20 \mathrm{~mL})$ containing pollen $(0.2 \mathrm{~g})$, one sponge $(1.5 \times 2 \times 1 \mathrm{~cm})$ moistened with honey solution and a honey bee pupa. Previous experience showed that SHB were not encouraged to lay eggs in egg laying slides (cut to fit the scintillation vials) but laid eggs normally in sponges. Hence, the damp feeding sponges were also used for egg laying. All vials (with two small vent holes in the lid) were put on a tray and kept in an incubator $\left(34^{\circ} \mathrm{C}\right)$ with moist newspaper around them. Egg laying was monitored every day for 3 days. Fresh food and feeding/egg laying sponges were provided daily. To facilitate counting, eggs were allowed to hatch and then frozen for later examination.

\subsection{Data analyses}

Since data on SHB mortality were not normally distributed due to early death of some beetles, a nonparametric (Kruskal-Wallis) test was used to determine differences among marked groups. Data on the flight activities were analyzed with two-sample $z$ tests for proportions to determine if there was a detrimental 
effect of notching on the proportion of beetles recovered from the nucleus colony and traps. For the data on fecundity of the multiple-pair group, a $t$ test was performed to determine the difference between average number of eggs per female per day between the notched and control groups. In the single-pair group, data were subjected to a repeated measure test to determine the difference between the average number of eggs per female per day between the notched and control (no notch) groups. A nonparametric Wilcoxon test was also performed to determine if females with multiple mates laid more eggs per day than those with a single mate. Before analyses, data were transformed using a square-root transformation to approximate normality (SAS version 9.2, SAS Institute 2008).

\section{RESULTS}

\subsection{Longevity of marked beetles}

Analysis of the number of days required to reach $50 \%$ mortality showed significant $\left(\chi^{2}=\right.$ 31.96, $P<0.0001)$ differences among the three mark types. The notched group took the longest time to attain $50 \%$ mortality with an average of $253.7 \pm 16.6$ days followed by the injured notched beetles having a mean of 121.2 15.7 days. Both the blue (mean $=10.0 \pm 6$ days) and the red (mean $=4.0 \pm 0$ days) dusted beetles took only a few days to reach $50 \%$ mortality. Similarly, the number of days required to reach $100 \%$ mortality was affected by the type of mark $\left(\chi^{2}=27.68, P<0.0001\right)$. The notched SHB had the longest survival (mean $=353.6 \pm 5.3$ days) followed by the injured notched beetles (mean= $193.6 \pm 38.8$ days). Blue (mean $=52.6 \pm 23.8$ days) and red (mean $=13.9 \pm 7.3$ days) chalk powders had the shortest survival.

Overall, our results showed that uninjured notched beetles survived the longest followed by those that were injured due to notching (Figure 2). For the beetles dusted with either blue or red powder, their mark came off quickly as the beetles walked on top or near the moistened cotton balls. Yet, these dusted beetles did not survive long.

\subsection{Recapture rate and effect of notching on flight activities}

When notched beetles were released in a nucleus colony, about $81 \%$ were still in the colony after 1 day (pooled data). We also

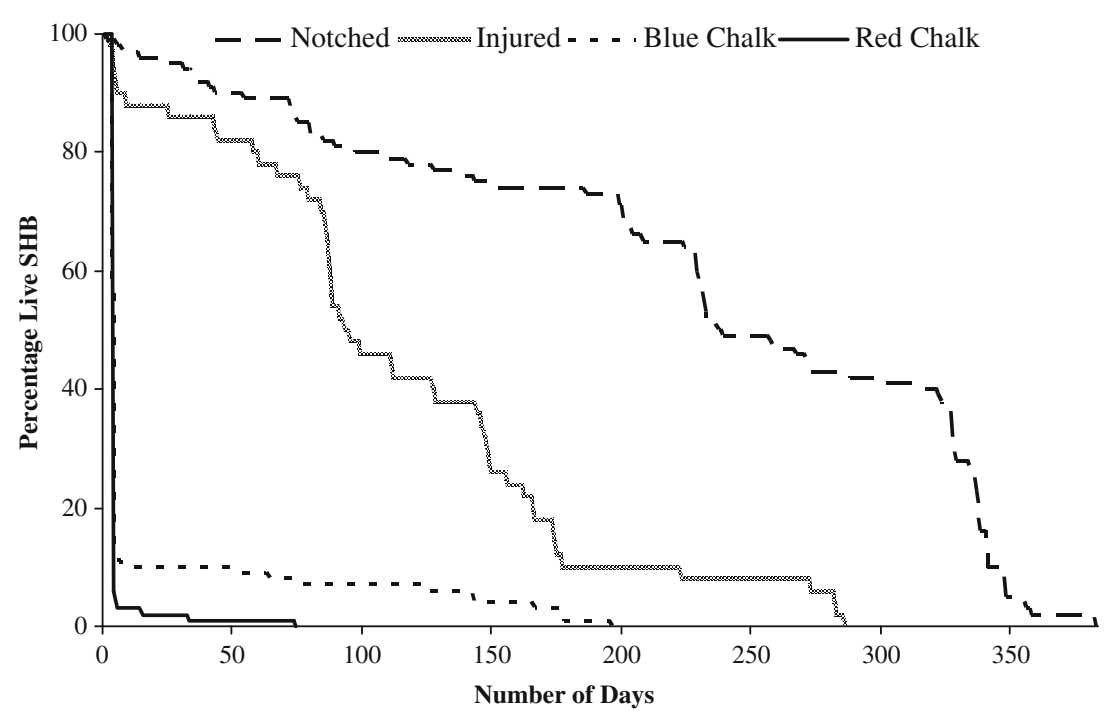

Figure 2. Survival of marked beetles: uninjured notched (larger dashed lines), injured notched (gray dots), blue chalk powder (smaller dashed lines), and red chalk powder (solid lines). The survival of the uninjured notched group was significantly $\left(\chi^{2}=27.68, P<0.0001\right)$ different from the three groups. 
recovered a high proportion (59\%) of notched beetles in the nucleus colony even when the marked beetles were released about $30 \mathrm{~cm}$ behind the colony $(z=13.41, P<0.0001)$. Notching had no negative effect on the ability of notched beetles to fly since they were able to fly into the pole trap with a mean of $66 \%(z=11.21$, $P<0.0001)$. When the recapture rate was compared between $2 \mathrm{~m}$ and the ground, a higher proportion $(z=4.12, P<0.0001)$ of notched beetles was recorded in the $2 \mathrm{~m}$ high traps than in the ground traps with mean catches of $38 \%$ and $24 \%$, respectively.

\subsection{Effect of notching on fecundity}

Overall, notched beetles laid significantly more eggs than the control group. In the rearing containers with multiple pairs of female and male SHBs, notched females laid an average of $171.70 \pm 11.20$ eggs per day $(t=2.96 ; P=0.041)$. For the beetles that were not notched, an average of $126.87 \pm 10.27$ eggs per female per day was recorded. A similar trend was observed in rearing containers with a single pair of female and male. Notched female beetles averaged about $70.02 \pm 5.45$ eggs per day while females of the control group (no notch) laid 57.97 \pm 5.12 eggs per day $(F=6.44 ; P=0.019)$.

Further, female SHBs maintained in groups with males laid significantly ( $W=575, P=0.001$ ) more eggs than those maintained with one male mate. With multiple pairs, a female laid an average of $149.28 \pm 12.11$ eggs per day while a female with one mate only averaged $63.99 \pm$ 5.46 eggs per day.

\section{DISCUSSION}

\subsection{Effectiveness of notching}

Although Goldwasser et al. (1993) notched scarabid beetles (size range, 10 to $25 \mathrm{~mm}$ ) on the elytra causing no harm to the beetles, notching of SHB elytra resulted in tearing. This problem was probably associated with their smaller size $(5-7 \mathrm{~mm})$ compared to that of scarabid beetles. The SHB's elytra are also shorter than the abdomen which made notching more cumbersome since it was difficult to spread the elytra. Also, notching of the elytra risks the cutting of the hind wings, which may have prevented them from flying.

Our results showed that marking adult SHB can be accomplished successfully by notching the posterior margin of the thorax. This study showed about $81 \%$ recovery of notched beetles when released inside nucleus colonies, and 59\% and $66 \%$ when notched beetles were released outside nucleus colonies and pole traps, respectively, inside a screen tent. Thus, notching of the thorax is more reliable than dusting which resulted in quick and high mortality of marked beetles. The early death of dusted beetles may be due to the powder blocking spiracles of adult beetles. In hairy insects, powder used for marking them is usually retained on the setae (Savalli and Fox 1999). SHB has smooth elytra and a smooth body. Thus, the spiracles of dusted beetles were less protected. Our results also indicated that this technique is more effective than painting the abdomen of SHB adults, which only resulted in about 13\% recapture efficiency (Nolan and Hood 2008).

\subsection{Effect on survival or behavior}

A good marking technique should not have adverse effects on the insect's survival or behavior (Southwood and Henderson 2000). SHBs were shown to live for 6 months when SHB adults were fed with honey and pollen (Lundie 1940), and 167 days for beetles fed with honey comb (Ellis et al. 2002). Fed with honey alone, notched beetles used in this study survived for nearly 1 year on average, more than twice as long as reported by Ellis et al. (2002). It is unlikely that notching increases beetles' survival because beetles that were presumed to be seriously injured as indicated by oozing hemolymph from the notched area only lived about an average of 195 days. Nevertheless, this group of injured beetles still lived longer than the beetles involved in the experiments evaluated by Lundie (1940) and Ellis et al. (2002). It appeared that the notched area was able to heal quickly since no 
secretion was further observed throughout the experimental period. Thus, this technique can be used for long-term studies.

Notching on the thorax seemed to increase reproductive potential of the notched beetles. This increased fecundity may be due to an increase in the level of octopamine (OA) caused by the stress from notching. OA levels have been found to increase in the hemolymph of locusts (Davenport and Evans 1984) and cockroaches (Bailey et al. 1983) during stressful handling and flight-or-fight behaviors (Orchard et al. 1993). Gruntenko et al. (2007) claimed also that $\mathrm{OA}$ affects insect reproductive function because a change in the OA content can result to changes in juvenile hormone $(\mathrm{JH})$ synthesis and degradation rates in Drosophila spp. JH appeared to function as a signal initiating egg maturation affecting fecundity of Bicyclus anynana during the first days of oviposition (Geister et al. 2008). We did not monitor egg laying for a long period of time. Thus, we do not know if the lifetime egg-laying capability of the notched beetles is increased. Further, OA may be released when stressed to mobilize energy stores needed to fuel flight-or-fight behaviors (Woodring et al. 1989). Since the beetles in this study were in closed containers and were not able to fly long distance, much of the activated energy was probably used in reproduction by the stressed notched beetles.

The ability of the notched beetles to fly was not affected. We recovered about $59 \%$ of the marked beetles from an active colony despite releasing them about $60 \mathrm{~cm}$ away from the hive entrance. Overall, we also recovered about $66 \%$ from pole traps hung up to $2 \mathrm{~m}$ high. These lower rates of recovery (as compared to an $81 \%$ recapture rate when notched beetles were released inside the colony) may be due to rainfall during two of the trials and from the overall attractiveness of the bait used. Nevertheless, nearly all beetles actively flew toward the ceiling and four corners of the 2.13-m-tall tent after being released. Since our study was conducted inside a tent, we are not sure if notched beetles can actually travel long distances. Regardless, this observation suggests that notching can be used to mark SHBs for several "mark-release-recapture" studies. Many aspects of SHBs behavior have yet to be studied. With this ability to mark and release adult SHBs in the field, their ability to disperse or seek host, preferences or movement patterns which can be influenced by age and sex of beetles, food availability inside the colony, or even honey bee stock will be elucidated.

\subsection{Advantages and disadvantages of dusting and notching}

SHBs' bodies are not particularly hairy like honey bees, thus the use of dusting was not an effective mark for SHBs. It also caused immediate high mortality because the amount of dust used was probably too much and had a toxic effect on adult beetles. It is also possible that marking with dusts or powder may have negative effects on honey bees.

As compared to the chalk powder, which caused high beetle mortality rate, notching is permanent and cannot be groomed off by worker bees. The mark (notch) is easily recognizable and very persistent; no re-growth of tissues was observed. Thus, this technique may be useful in determining the longevity of beetles inside the colonies under field conditions. This technique is easy and quick for marking a group of beetles. Several hundreds of beetles can be marked in a day. Notching is also simple and inexpensive; only a pair of scissors is needed which is widely available (Goldwasser et al. 1993).

Also a coding system for groups of beetles can be employed. The position of the notches may be used to differentiate beetles: a notch on the left or right margins can be used to distinguish sex of beetles, classify ages of beetles, identify sources of beetles, or categorize them based on release dates. The use of square notches with triangular ones may also be helpful in differentiating cohorts of beetles. Further, SHB adults are small and holding live ones can be a challenge. Perhaps, beetles can be anesthetized with carbon dioxide or they can be quickly chilled for easy handling of beetles while notching. A marking technique is essential to 
the success of many studies of population biology (Goldwasser et al. 1993).

\section{ACKNOWLEDGMENT}

We thank A. Prudente, T. Stelzer, J. Wales, and G. Delatte for their technical help. This research was completed in cooperation with the Louisiana Agricultural Experiment Station.

Marquage des petits coléoptères des ruches par encoche thoracique: effets sur la longévité, l'aptitude au vol et la fécondité.

Aethina tumida / marquage / thorax / méthode de capture recapture / survie / fécondité / activité de vol

\section{Markierungen des Kleinen Beutenkäfers durch Thoraxeinkerbungen.}

Aethina tumida / Markierung / Kerbe / Wiederfang / Überlebensrate / Fekundität / Flugaktivität

\section{REFERENCES}

Arbogast, R.T., Torto, B., van Englesdorp, D., Teal, P.E.A. (2007) An effective trap and bait combination for monitoring the small hive beetle, Aethina tumida (Coleoptera: Nitidulidae). Fla. Entomol. 90, 404-406

Bailey, B.A., Martin, R.J., Downer, R.G.H. (1983) Haemolymph octopamine levels during and following flight in the American cockroach, Periplaneta americana. Can. J. Zool. 62, 19-22

Connor, L. (2011) Wipe out! the big island in crisis. Bee Cult. 139, 56-60

Davenport, A.P., Evans, P.D. (1984) Stress-induced changes in the octopamine levels of insect haemolymph. Insect Biochem. 14, 135-143

de Guzman, L.I., Frake, A.M. (2007) Temperature effects on the life history of Aethina tumida (Coleoptera: Nitidulidae). J. Apic. Res. 46, 88-93

de Guzman, L.I., Frake, A.M., Rinderer, T.E., Arbogast, R. T. (2011) Effect of height and color on the efficiency of the small hive beetle (Coleoptera: Nitidulidae) pole traps. J. Econ. Entomol. 104, 26-31

Ellis, J.D., Neumann, P., Hepburn, H.R., Elzen, P.J. (2002) Longevity and reproductive success of Aethina tumida (Coleoptera: Nitidulidae) fed different natural diets. J. Econ. Entomol. 95, 902-907

Gangwere, S.K., Chavin, W., Evans, F.C. (1964) Methods of marking insects, with special reference to Orthoptera (Sens. Lat.). Ann. Entomol. Soc. Am. 57, 662-669
Geister, T.L., Lorenz, M.W., Hoffmann, K.H., Fischer, K. (2008) Effects of the NMDA receptor antagonist MK-801 on female reproduction and juvenile hormone biosynthesis in the cricket Gryllus bimaculatus and the butterfly Bicyclus anynana. J. Exp. Biol. 211, 15871593

Goldwasser, L., Schatz, G.E., Young, H.J. (1993) A new method for marking Scarabaeidae and other Coleoptera. Coleopt. Bull. 47, 21-26

Gruntenko, N.E., Karpova, E.K., Alekseev, A.A., Chentsova, N.A., Bogomolova, E.V., Bownes, M., Rauschenbach, I.Y. (2007) Effects of octopamine on reproduction, juvenile hormone metabolism, dopamine, and 20hydroxyecdysone contents in Drosophila. Arch. Insect Biochem. Physiol. 65, 85-94

Hagler, J.R., Jackson, C.G. (2001) Methods for marking insects: current techniques and future prospects. Annu. Rev. Entomol. 46, 511-543

Lundie A.E. (1940) The small hive beetle, Aethina tumida. Science Bulletin 220. Union of South Africa, Dept. of Agriculture and Forestry (Entomological Series \#3). $30 \mathrm{pp}$

Nolan IV, M.P., Hood, W.M. (2008) Mark, release, and recapture techniques for the small hive beetle. Am. Bee J. 48, 558-559

Orchard, I., Ramirez, J.M., Lange, A.B. (1993) A multifunctional role for octopamine in locust flight. Annu. Rev. Entomol. 38, 227-249

Polivka, J.B. (1949) The use of fluorescent pigments in a study of the flight of the Japanese beetle. J. Econ. Entomol. 42, 818-821

SAS Institute (2008) SAS user's guide, version 9.2. SAS Institute, Cary

Savalli, U.M., Fox, C.W. (1999) The effect of male size, age, and mating behavior on sexual selection in the seed beetle Callosobruchus maculatus. Ethol. Ecol. Evol. 11, 49-60

Southwood, T.R.E., Henderson, P.A. (2000) Ecological Methods. Blackwell Science, Oxford

Taft, H.M., Agee, H.R. (1962) A marking and recovery method for use in boll weevil movement studies. J. Econ. Entomol. 55, 1018-1019

Winder, L. (2004) Marking by abrasion or branding and recapturing carabid beetles in studies of their movement. Int. J. Pest Manag. 50, 161-164

Woodring, J.P., Mcbride, L.A., Fields, P. (1989) The role of octopamine in handling and exercise-induced hyperglycaemia and hyperlipaemia in Acheta domesticus. J. Insect Physiol. 35, 613-617

\section{Footnote}

Mention of trade names or commercial products in this publication is solely for the purpose of providing specific information and does not imply recommendation or endorsement by the United States Department of Agriculture. 